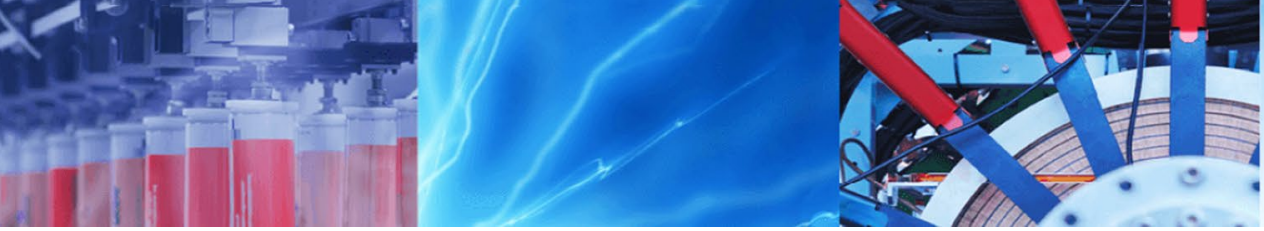

Research Article

\title{
Securing sustainability in Indian agriculture through civilian UAV: a responsible innovation perspective
}

\author{
Anjan Chamuah $^{1}\left[\right.$ Rajbeer Singh ${ }^{1}$
}

Received: 20 September 2019 / Accepted: 11 December 2019 / Published online: 18 December 2019

(c) Springer Nature Switzerland AG 2019

\begin{abstract}
Emerging technology like civilian unmanned aerial vehicle (UAV) has the potential to exert an impact on agriculture production and crop damages assessment. Securing sustainability in agriculture requires accountability and responsibility of the actors engaged in the deployment of the civilian UAV due to associated deployment risks and unintended consequences. UAV technology has the potential to replace remote sensing technologies like satellite imageries and piloted aircraft used in the crop insurance business. The governance of deployment of UAV technology in India is a complex challenge when a well-developed regulatory system is not in place and diverse actors involved in the deployment and operation of civilian UAV for agricultural applications. Therefore, two main questions, how UAV innovations can lead to sustainability in Indian agriculture and how are the issues of governance of civil UAV innovations in crop insurance applications addressed, are dealt with. The responsible innovation approach is adopted as a theoretical framework. The exploratory and qualitative study used in-depth interviews, and the interviewees were selected through snowball sampling technique. The results suggest that in the governance of emerging technologies like UAV certain values such as trust, transparency, safety, autonomy, and environmental friendliness assumed high significance. Findings also suggest that UAV has the risk-taking ability in adverse weather condition. The UAV technology also creates values (social, economic and environmental) for deployment in the crop insurance business in India.
\end{abstract}

Keywords Civilian UAV · Sustainability · Responsible innovation · Agriculture insurance · Accountability

\section{Introduction}

Sustainable agriculture is a broad area which encompasses issues relating to financial, social, human, environmental and biological resources in the development of technology and social institutions [1]. Environmental preservation, economic returns and sociological factors associated with quality of life consist of sustainability in agriculture [2]. Nowadays, there is an emerging challenge in the agriculture sector, including food processors, food producers and the distributors of food due to the controversial mix of technological, scientific and public concern which further integrate and juxtapose technological risk, societal responses and environmental pressures [3]. Achieving sustainable agro-food system is not an easy task unless it adopts and disseminates new and emerging technologies embedded in new economic, social, institutional and cultural relations [4]. The functioning of these technologies also depends on other essentials such as principles, different cultural connotations, market performances, infrastructures and the network of supply and maintenances [5].

Sustainability in agriculture cannot be discussed in isolation; instead, it should be evaluated as a system [1], consisting of different components coordinated and communicated through various networks and channels supported

Anjan Chamuah, anjan.chamuah@gmail.com $\mid{ }^{1}$ Centre for Studies in Science Policy, School of Social Sciences, Jawaharlal Nehru University, New Delhi 110067, India. 
by both formal and informal institutions [6]. Sustainability is, thus, the ability to meet societal needs without any significant adverse impacts [7]. However, sustainable agriculture development is defined as:

Agriculture system which over the long run enhances environmental quality and the resources base on which agriculture depends, basic human food and fibre needs are economically viable and improves the quality of life of farmers and society as a whole [8].

The advent of new and emerging technologies added a new dimension to agriculture sustainability. The emerging technologies are trying to provide a solution to almost every problem of human life and their surrounding ecosystem [9]. From decision making to human resource all are affected by new technology [10] and have a direct impact on the economy and society [11]. However, the arrival of these problem-solving technologies also raises questions about their efficiency, validity, reliability and sustainability (social, economic and environmental). Civilian unmanned aerial vehicle (UAV) as one of such emerging technology is being deployed in India agriculture for the insurance business. The operation and management of civilian UAVs have created multiple issues for its monitoring, regulating and controlling by authorities. This emerging technology possesses security and safety concerns among users, residents, government authorities and civil societies. There are also concerns regarding its sustainability in Indian agriculture insurance. Governance of civilian UAV and ensuring sustainability (social, economic and environmental) in its deployment to agriculture insurance is a challenging task in a developing country like India with different socio-cultural norms. Therefore, the issue is that how to ensure the accountability of deployment of UAV technologies in the Indian scenario. To address the above issues and concerns, this paper has dealt with the two questions: that how UAV innovations can lead to sustainability in Indian agriculture and how are the issues of governance of civil UAV innovations in crop insurance applications addressed.

The innovation approach, like Responsible Innovation (RI) [12-15], claims to addresses the issue of governance of emerging technologies for ensuring sustainability and accountability. RI thus becomes significant as a theoretical framework for this paper. Henceforth, by adopting RI as a theoretical framework, the paper addresses all the research questions.

The rest of the paper is organised as follows: Sect. 2 describes the theoretical framework used for the study, i.e., Responsible Innovation Approach. Section 3 discusses the methodology adopted to carry out the research study. Section 4 provides an overview of the issue of sustainability embedded in agriculture through UAV innovations. Section 5 addresses the governance issues associated with civil UAV innovations in Indian agriculture. Section 6 discusses the various issues related to sustainability, governance and culture-specific values hovering around civil UAV deployment in Indian agriculture. Section 7 includes the main findings and the concluding remarks of the study.

\section{Responsible innovation: a theoretical framework}

Sustainability is an essential aspect of innovations. Innovation can be said to be successful only if it can retain social, economic and environmental sustainability [16]. From the prevailing theories of innovations, we have seen that firms bring new ideas to the market as products, processes, services or ways of organising [17]. However, systems of innovation like National Innovation System [18, 19], Sectoral Systems of Innovation [20, 21] and Technological Innovation System [22-24] did not pay much attention to sustainability (economic, social and environmental). RI, however, focusses on the aspect of sustainability by taking into account the risks involved in the deployment and ensuring care while adopting new and emerging technology like civilian UAV. Therefore, RI has been adopted as the theoretical framework for this study. The definition of RI proposed by Singh and Kroesen [25] is reproduced hereafter:

Responsible innovation means to be caring or ensuring care for certain values for social, economic and environmental sustainability by engaging in anticipation, reflexivity, deliberation, responsiveness and participation for bringing up any change in any idea, product, process, method, way of doing business, technology, etc. in order to bring them into a specific market or use them in a society.

Apart from it, the RI approach has three objectives to secure social, economic and environmental sustainability $[14,25,26]$. Concepts like care and responsiveness are also ingrained within it [27], which the other theories of innovation did not pay much attention. $\mathrm{Rl}$ is an approach which talks about taking care of the future through collective stewardship of science and innovation in the present [13]. The new technology should not hurt society, neither the environment in which it sustains. The technology should also be affordable. Further, Von Schomberg [12] defined responsible research and innovation which talks about ethics, sustainability and society, which is reproduced hereafter:

A transparent, interactive process by which societal actors and innovators become mutually responsive to each other with a view to the (ethical) accept- 
ability, sustainability and societal desirability of the innovation process and its marketable products (in order to allow a proper embedding of scientific and technological advances in our society).

Moreover, RI is embedded with certain values. Values can be universal or culture-specific [14, 28]. Values are indicators or philosophical representation of certain desired functionalities, effects and benefits [26]. The values thus help in philosophising the technological and innovational approach [9]. The role of values is mainly focussed on the means to achieve aims [29]. However, values are not embedded within a technology; somewhat, they are implicated through engagement [30] in society. The objective of values is securing sustainability (social, economic and environmental). So, in any governance, our goal is to ensure sustainability and viability. It should not have any adverse impact on the society and environment. Any law which is coming should not have any adverse effect on innovations. Thus, the RI approach helps us in building a new governance structure for civilian UAV deployment in India and also secures the sustainability dimensions of the technology.

The next subsection provides an overview of how the research is done. The methods, tools and techniques used in data collection are illustrated in the section.

\section{Methodology}

The research is qualitative and exploratory from the perspective of the technology and the theoretical framework deployed in the study of Indian agriculture insurance. The literature on agriculture sustainability, UAV, responsible innovation, governance of technology, agriculture insurance and research methodology was surveyed both online and offline based on a literature survey questionnaire. ${ }^{1}$ The literature survey questionnaire consisted of a set of questions in probing format, and all the questions are printed in English.

In-depth interview was also carried out based on an interview schedule to get the responses from the interviewee on the objectives of the study. The interview schedule used for the interview consisted of a set of questions, which were open-ended and printed in English. Snowball sampling technique ${ }^{2}$ was used to select the interviewee

\footnotetext{
${ }^{1}$ A literature survey questionnaire (LSQ) is a research tool which consists of a set of questions. The questions in the LSQ are openended. The questions probed in the LSQ helped in the collection of pieces of literature required to fulfil the research goals.

2 Snowball sampling method is a non-probability sampling method; it is used when the population is hard-to-reach or hard-toidentify as there is no sampling frame [31] or in other words. The
}

since the characteristics to be possessed by the samples were rare and difficult to find [32]. The Civil UAV, the prime focus of the study, is a new and emerging technology, not yet fully implemented in Indian crop insurance applications. So, snowball sampling technique helped in getting connected with the samples associated with governance and deployment of the technology, which was otherwise a difficult task.

The research objectives were substantiated by conducting in-depth interviews at Mahalanobis National Crop Forecast Centre (MNCFC), Skymet, Director General of Civil Aviation (DGCA), North East Centre For Technology Application \& Reach (NECTAR) and Bajaj Allianz General Insurance Company. All these organisations are based in Delhi. The interviewees are agriculturalists, scientists, researchers, engineers, policy analysts and consultants associated with these organisations and are the main actors of governance and deployment of civil UAV in Indian agriculture. Verbatim notes were gathered during the interviews supported by voice recording and analysed according to the research objectives of the study. The next subsection discusses the sustainability issues embedded in Indian agriculture.

\section{Sustainability to agriculture: UAV innovations}

Sustainability in agriculture is a complex subject of study which is a confluence of combined technological, social and institutional innovations in agriculture; within the governance of actors' interactions, the role of innovation policies is crucial which may be specific to a sector, country or a particular technology [33]. There are many challenges faced by the agriculture sector, such as climate change, biodiversity loss, water scarcity, drought, floods and soil degradation, which demands a transition to a sustainable mode of production and consumption [34].

Shifting and making transitions towards sustainable agriculture and food systems call for innovative solutions and appropriate technologies such as civilian UAV. However, firstly, what is a civilian UAV. A civilian UAV or drone is a new and emerging technology which provides a platform for communication, interactions and coordination of various actors in the agriculture sector for sustainability (social, economic and environmental). Moreover, a pilotless aircraft is known as UAV or a drone. The UAV is also

Footnote 2 (continued)

members of the population are somewhat interconnected and know each other and direct the different prospective samples, and this is how the samples are gathered. 
given meaning by International Civil Aviation Organisation ICAO [35], as reproduced hereafter:

An unmanned aerial vehicle is a pilotless aircraft, in the sense of Article 8 of the Convention on International Civil Aviation, which is flown without a pilot-incommand on-board and is either remotely and fully controlled from another place (ground, another aircraft, space) or programmed and fully autonomous.

The UAV consisted of different parts, viz. a single board computer, a remote control (RC) aircraft, an inertial measurement unit (IMU), a multispectral camera, a wide area augmentation system (WAAS), a global positioning system (GPS), a flight controller, a pulse width modulation (PWM) switch, a video transmitter and a wireless router [36]. The flight control unit (FCU) is the central part of any UAV which is capable of processing the information given by a remote pilot into the navigational task [37]. Civil UAV is known for high speed and flexible routes; however, it has pre-defined hovering time on the sky restricted by a limited power supply [38].

In India, civil UAV is deployed in many sectors like agriculture, insurance, energy and utilities, infrastructure, mining, media and entertainment [39]. The civilian UAV deployment in agricultural insurance sector triggers an interesting research question of how UAV innovations can lead to sustainability in Indian agriculture is dealt with hereafter. Agriculture productivity has been affected by multiple damages to crops during whole crop cycles. The Indian government has provisions to protect against the risks in the agricultural sector by providing crop insurance. There are complaints from the farmers that they pay the premium to the insurance companies, but they never get paid for the damages to their crops. Since crop insurance has been extended few cash crops to multiple non-cash crops too, the mear inclusion of more numbers of crops under the insurance could not give enough and minimal support to farmers against crops losses in India. This has made an agricultural activity for farmers highly unsustainable from not only economically but socially and environmentally too. The farmers could not get enough trust in new emerging technology due to non-beneficial outcome. The cost of farmers has gone up with a similar increase in realised prices of crops and returns on investment. Despite the eagerness of insurance companies and government to help farmer through crop insurance, farmers could not get paid damages for their insured crops. The issue was around the assessment of the damages to the crops. Since there were not enough viable and transparent scientific tools available for the government, insurance companies and farmers to prove that what were the damages to crop so that they could decide that how much damage in terms of money. This scenario has demanded deployment of civilian UAV technologies for identification and assessment of crop damages and other agricultural services.

As in the sense of Responsible Innovation, if any innovation can ensure certain values, which further leads to sustainability, then that innovation gets better acceptance and promotion. Further, the issues of governance also addressed in better ways. The civilian UAV deployment in India has led to multiple positive outcomes. The analysis of interviews and field study suggest that civilian UAV deployment has addressed many problems faced related to the level of crop damage and areas of damage.

For being a responsible innovation, UAV innovation got embedded multiple values which have created sustainability into the agricultural insurance sector. Some of the values which are identified and can be responsible for creating sustainability in agriculture are discussed hereafter. It also highlights how they have created sustainability in agriculture.

\subsection{Capability}

It is the ability or power to do something. From the interview with Dubey [40], it is evident that in the agriculture sector in India, the technology is used in the compilation of plant crops, calculation of fair crop loss percentage, crop supervision and crop maintenance. In agriculture, the technology has enormous applications in crop imaging, spraying of seeds, fertilisers and pesticides [41]. A drone can inspect up to 1000 acres of farmland a day, making survey faster and accurate than planes or satellites [42]. In India, drones are now compulsory under Pradhan Mantri Fasal Bima Yojana (PMFBY) scheme. The interview with Lalan [43] illustrates that civil UAV helps in the detection of crop failure and crop damage assessment which are caused by flood, drought and other natural disasters. Earlier, detection of crop damage by natural disasters was entirely dependent on satellite imageries which are now being replaced by high-resolution images supplied by drones.

\subsection{Transparency}

The clarity about kind of damage, area of damage, level of damage and time of damage has become real after deployment of civilian UAVs in India [43]. The data about damage can be interpreted by the farmers, insurance assessor and government without confusion and bias since they are visible and accessible to all stakeholders. The farmers can see instant results about the assessment. Even the data and assessment of damage by civilian UAV can be stored on computers for later usage in case if there is any dispute between farmers and insurance companies. The deployment of civilian UAV has imparted the 
Table 1 Impact of civilian UAV on agriculture sustainability. Source: Own analysis, mainly based on the study by [14, 34]

\begin{tabular}{|c|c|c|}
\hline Sustainability dimensions & Positive values imparted & Negative values \\
\hline Environmental & $\begin{array}{l}\text { Helps in careful use of resources (water, land and } \\
\text { energy) } \\
\text { Efficient in the spraying of fertilisers and pesticides }\end{array}$ & $\begin{array}{l}\text { A collision can cause harm to birds and insects } \\
\text { Environmental degradation can be caused due to } \\
\text { excessive use of pesticides through civil UAV }\end{array}$ \\
\hline Social & $\begin{array}{l}\text { Helps in building trust among farmers } \\
\text { It ensures transparency and traceability in settling } \\
\text { claims } \\
\text { Timely and secure access to data } \\
\text { It helps in communication, coordination and participa- } \\
\text { tion of the actors } \\
\text { It is safe to handle and operate }\end{array}$ & $\begin{array}{l}\text { There can be a threat to privacy where it is flown } \\
\text { Security issues can also arise if it flies in no-fly zones }\end{array}$ \\
\hline Economic & $\begin{array}{l}\text { Effective in settlement of claims } \\
\text { Accessible for all categories of farmers once they have a } \\
\text { Unique Identification Number (UIN) }\end{array}$ & $\begin{array}{l}\text { Not affordable for all types of farmers due to the high } \\
\text { cost }\end{array}$ \\
\hline
\end{tabular}

transparency of the process of damage assessment and its calculations.

\subsection{Trust}

Trust is a human reliance on natural or machine phenomena $[29,44]$. According to Lalan [43], civilian UAV provide timely and accurate information aided by its infrared, multispectral and hyperspectral sensors which are proving useful in settlement of claims for farmers who are insured under the crop insurance scheme. Thus, technology is helping to build trust among the farmers by ensuring transparency and traceability. The transparency and traceability of data provided by civil UAV further makes it accountable and entwine the values of responsibility in the overall civilian UAV innovations in Indian crop insurance scheme.

\subsection{Affordability}

The small civilian UAVs can be redeployed so that their cost of operation and deployment goes down. The crop insurance companies can afford these drones as the benefits of deployment in terms of economic and resolving issues of damage payment outnumber the cost of investment. Dubey [40] and Ray [45], argued that civilian drone is highly affordable to the users in the agricultural insurance sector. The economic viability is one of the essential aspects of sustainability for civilian UAVs in India. The economic viability supported by smaller drone leads to better adoption of such innovation to impart agricultural sustainability for a vast country like India.

\subsection{Efficiency}

Efficiency is the ratio of effort applied to achieve a particular result $[30,46]$. From the interview with Manda [47], it became evident that the advent of civilian UAV in crop insurance has replaced other RS technology due to its efficiency in remote distance data collection. The main advantage of UAV is that it collects remote sensing data unhindered in adverse weather condition even under the cloud [48]. Thus, civilian UAV has the risk-taking ability and also ensures care and responsiveness of the data gathered from remote locations.

So far, it is revealed that deployment of civilian UAVs has imparted important values which leads to the creation of sustainability in agriculture.

Table 1 illustrates the value imparted by civilian UAV in Indian agriculture, further contributing to the sustainability (social, economic and environmental) dimensions.

The table shows both the positive and negative values imparted by civil UAV in Indian agriculture insurance. The negative values should be taken care of by embedding values which are socially acceptable, economically affordable and environmentally viable to make the innovations responsible and accountable. Apart from it, the technology is a new intervention to Indian agriculture. It is only in 2016 that civil UAVs got introduced in crop insurance. The DGCA implemented the policy for flying drones in India only in December 2018. The technology is not yet fully implemented in all the agriculture states in India. So, for effective dissemination of the technology and securing sustainability in the agriculture sector demands to ensure care for the negative values and at the same time upholding and promoting positive values which are beneficial for the society, economy and the environment. 
The next section discusses the governance issues of civilian UAV innovations in Indian agriculture insurance sector and how they can be addressed.

\section{Governance of innovations for sustainability}

An effective governance system is essential for ensuring sustainability. Governance refers to a set of actors and institutions that are drawn from but also beyond government [49]. It is a process which has the potential to empower citizens through participation and consultation process [50]. Governance of emerging technology should be viewed from the historical context based on some flexibility in new developments [12]; coordinated between the regulator and the regulated [51]. Several aspects, like cooperation, collaboration, accountability and transparency, are essential for UAV technology governance [52]. Therefore, how to address the issues of governance for civilian UAV innovations in crop insurance applications.

In India, many actors are involved in the governance of civilian UAV. The main actors are DGCA, Ministry of Agriculture, Ministry of Home Affairs, Ministry of Defence, Insurance companies, farmers, local administration where the technology is deployed, scientific organisations like MNCFC and NECTAR. There is a network of coordination, communications and interactions among all the actors [20] of civil UAV innovations in Indian agriculture insurance supported by some formal institutions [6].

From the interview with Ray [45], it was revealed that the governance of civilian UAV innovations in Indian agriculture insurance is a humongous task due to the diversity of the actors involved. Thus, governance recognises the power dependence involved in the associations between various actors in collective action [49], which further has a direct impact on innovations [53]. Effective governance promotes innovations, whereas an ineffective one can suppress it. Innovation is crucial to sustainable agriculture [4]. Hence, effective governance of innovations is utmost necessary for sustainable agriculture.

Moreover, values like accountability, safety, privacy, autonomy, transparency and responsibility are given due importance in the governance of new and emerging technology like civilian UAV. Accountability ensures answerability for undesirable action or duties [54]. Thus, values are measured and represented regarding performance and consequences which should be socially acceptable, economically affordable and environmentally viable [25]. The values depend on the way technology is defined and used. Proper embedding of values also strengthens the governance structure of the technology.
There are some culture-specific values, promoting of which are essential for effective governance of civil UAV in India. These values are discussed hereafter in the context of addressing the issues of governance.

\subsection{Safety}

Safety means the absence of risk and hazards $[46,55]$. From the interview with NECTAR [56], it became evident that safety is one of the crucial issues in the governance of emerging technology like civil UAV. The safety of the user, environment, state assets and the public where drones are deployed should be considered during the governance of such new and emerging technology. The drone pilot should be responsible and ensure the safety of the farmers, crops, insects, animals and other public assets where the technology is deployed. Irresponsible handling of drones can also hurt the pilot. Henceforth, the drone pilot should also consider the safety measures during the take-off and landing of the UAVs and should adhere to the visual line of sight (VLOS) ${ }^{3}$ to avoid any collisions. The interviews with Dubey [40] and Ray [45], from MNCFC, also gave importance to safety issues. According to them, safety is directly linked with the damage of crops caused by various environmental and pathological conditions. It is also essential during the assessment of crops. So, if we embed the value of safety as a part of the drone deployment and also as part of responsible innovation approach, then the innovations can be claimed as safer. Thus, by ensuring the value of safety in drone deployment makes governance easier for civil UAV innovations in Indian crop insurance applications.

\subsection{Privacy}

Privacy of an individual is also an important issue when such technology is deployed in agriculture insurance. In rural India, the agriculture community has its own culture and way of living. Technology, like civil UAV, may pose a threat to their privacy. Interview at DGCA [57] emphasised that proper training to the pilots of the drone can control the privacy issues of the rural population. The pilot should maintain the ethics and privacy rights of the people while deploying the drone. The pilot should be responsible for violation of such privacy rights of the individual. Responsible innovation thus suggests that these values should be

\footnotetext{
${ }^{3}$ VLOS means the drone is within the visible range to the pilot. If the drone goes beyond a hill or tress, then it is not visible to the pilot and can be called as beyond visual line of sight (BVLOS). BVLOS it is highly unsafe to fly a drone as it can cause accidents and can hit other drones.
} 
embedded in the training and implementation process of innovations to obtain the goal of sustainability.

Moreover, securing values like safety and privacy of the rural population bolsters the accountability of the actors engaged in the deployment and governance of the new technology. Adhering to issues of safety, security and privacy is also the key to sustainable implementation and governance of the technology. Thus, promoting the culture-specific values of the agriculture community and strengthening the institutions moulding the governance of the technology would ensure higher social acceptability and ethical viability.

The next subsection discusses the various issues related to sustainability and culture-specific values hovering around the deployment and governance of emerging technology, including civil UAV in Indian agriculture and also in countries across the world.

\section{Discussions}

The prime objective of the study is to ensure sustainability. It has been already explained in the previous sections that sustainability here refers to social, economic and environmental issues. When the issue of ecological sustainability is discussed in agricultural practices, multiple consequences are coming out. Overutilisation of pesticides, herbicides and insecticides create hazards in agriculture. The dosage used in agriculture is multiple times higher than the subscribed level. Henceforth, the current agriculture practices create a high level of unsustainability to the environment. High utilisation of chemicals can affect ecology, human and animals leading to disease like cancer and animal ill health [58]. Thus, the infusion of the drone can monitor the overuse of chemicals in the agriculture practices, and a drone can also help in spraying of the requisite amount of fertilisers in the specific area. The farmers can also be included in the process of deployment of fertilisers who nowadays have a digital Aadhaar number in India, which can be linked to the 'digital sky' platform of drone governance. The local administration and other regional actors thus can be communicated, connected and networked through the aerial spraying of fertilisers in a particular agriculture field. The local actors thus become accountable for any unhindered consequences of the deployment of civil UAV.

The drone can also monitor crop cutting experiments $(\mathrm{CCEs})^{4}$ and damages to crop. There are different types of injuries caused by pest, insects, drought, flood, soil erosion

\footnotetext{
${ }^{4}$ CCEs are regularly conducted to obtain fair, precise and accurate estimate of yield of principal crops. The experiments are conducted through stratified random sampling technique by taking block as a primary unit [59].
}

and wild animals which the drone can very efficiently identify and detect. The drone can be a dispute-resolving tool in settling claims for crop failures. It can strengthen the trust between the insurance companies and the farmers by providing data about CCE and crop failures. Thus, along with environmental care, the drone can also provide social security to farmers by its multidimensional prospects. The farming community in India hardly have any friend to recover their premium. So, the drone is like a saviour for the community who helps in efficient settlement of the claims resulting in confidence in the society. It is thus a new institutional way of authorisation supported by the $U A V$, which provides ample scope of verification of claims. The authenticity augmented by drone brings a change into the system heralding social sustainability.

The detection of damages and aiding in CCE helps in increasing the productivity of the farming community. It can also help in equal distribution of chemical fertilisers in the entire country with the surplus amount. The farmers get benefitted on the spending and revenue side of fertiliser utilisations. The soil assessment done by drone mounted with sensors helps in detection of soil nutrients and moisture required for the growth of the crop. Accordingly, the farmers can sow crops based on the soil content, which further reduces the economic vulnerability attached to crop failures and damages. Henceforth, it infuses a higher level of economic sustainability.

In India, smallholdings (2-5-acre land) farmers dominate agriculture. Numerous farmers and small landholdings create a high level of diversity in Indian agriculture. No farmer in India has 100 acres of contiguous land for a single crop. Because multiple crops are sown in the landholdings of the single farmer, the crops to be planted are decided by individual farmers since there is no interference from the government in the selection of crops for sowing. Within the same crops also there are different varieties planted and sown in India. Some seeds are highyielding and some are clones. Thus, the agriculture sector in India is convoluted with multiple diversities.

The major challenge comes in the deployment of drones in the small landholdings. Who will deploy? Who are the main actors and institutions governing drone deployment? The first challenge is that people do not have enough money to pay to drone companies. The second challenge is that whether the government would provide drone service free of cost or the insurance company should invest. The government has digitalised the land records in India. Through direct benefit transfer (DBT), money is transferred directly to the beneficiaries' accounts. Thus, the government has set a platform to govern the technology. Now, the challenge is how to administer the deployment and usage of civil UAV in India. As per the PMFBY, there is a mandate that the government would provide insurance 
for certain types of crops in India, and the farmers need to pay the premium.

One governance framework is prepared by DGCA where policy framework and regulations are embedded. Following the norms prescribed by DGCA, it can be used by any companies or individuals, wherein the pilots are issued UIN to fly drones up to a prescribed height in the sky.

India should bring further legislation to regulate civil UAV governing body. The governing body should give access to the users and pilots of drones. The governing body should be connected with the district-level officers who can grant direct permission for the operation of drones in their districts.

Similarly, the study has found that drones are in use worldwide in various sectors. The international UAV market has proliferated in the past years. A recent study from Grand View Research estimated the global commercial drone market size to be $\$ 552$ million in 2014 and anticipated to grow to $\$ 2.07$ billion by 2022 , with agriculture dominating other drone sectors [60]. In Colombo, International Water Management Institute (IWMI) deployed drones to monitor rice cultivation in the water-scarce area of Anuradhapura. The institute used red, green and blue colour and near-infrared sensors to capture image over the paddy fields [61]. Water is the deciding factor in rain-fed agriculture system in Africa. UAV technology is helping to design and construct a cost-effective irrigation infrastructure [62]. The desert locust is one of the most dangerous pests in the world. This migratory pest has voracious appetite unmatched in the insect world. UAVs could be deployed in locust-affected areas in the desert to collect high-resolution imagery of green vegetated areas [63]. Panama's indigenous communities started using UAVs since 2015. The indigenous communities of Panama have successfully used UAVs to document illegitimate land occupancy and illegal land logging by non-indigenous people [64].

Moreover, apart from civil UAV, other technologies like digital farm management, precision farming, bioremediation, biological pest control and organic farming techniques are also proving to be efficient technologies, and if used with care and responsibility they can promote agriculture sustainability $[65,66]$. Use of biotechnology can reduce the use of pesticide, furthers crop improvement with lesser or no human and environmental impact [2]. However, technology such as precision agriculture reduces environmental degradation by applying the appropriate quantity of fertilisers and pesticides, with the aid of information technology, robotics and sensors when it is required and where it is required [67]. Therefore, it also helps in nutrient management and retaining soil quality and texture. In a water-scarce country like Israel, technology like drip irrigation is proving to be useful in water conservation and reduce drainage [68].

Similarly, in the tea sector of Assam, India, the advent of technology like sprinklers irrigation, planting machine, pruning machine, plucking machines and various postharvest processing techniques have revolutionised the sector [69]. The digital farm management system (DFMS) in China, apart from the management of crops, also involves the management of inputs, inventory and quality [70]. According to Yang et al. [70], DFMS does financial management, profitability analysis, streamline processes, improve accessibility and handle broad data efficiently.

All agriculture practices, including from intensive conventional farming to organic farming, have the potential to be sustainable depending on farmer's choice of appropriate technology and management practices within the right-policy framework supported by the specific agroecological environment [66]. However, the study is not devoid of limitations. The UAV is an emerging technology which is not yet fully implemented in the agricultural states in India. The study area is not Pan-India, but only a state. Additionally, the rules and regulations are also evolving. Thus, taking consideration of the diversity of people, culture, geography and climate of India, deploying such technology as a drone is not an easy task and formulating rules and regulations for governance is a challenge.

The next subsection provides the concluding remark and the final reflection about the research study.

\section{Conclusion}

The Responsible Innovation approach which is a processbased approach with five dimensions helps in fulfilling the objectives of sustainability in agriculture while embedding values like trust, transparency, traceability, privacy, safety and affordability, and ensuring participation of all the actors of civilian UAV innovations deployed in Indian agriculture insurance. The deployment of civil UAV in agriculture insurance is not an easy task due to the diversity of the actors involved. Moreover, to secure sustainability also demands to fulfil the social, economic and environmental sustainability, which the technology is contributing to some extent by becoming user-friendly, efficient and pollution-free. Civil UAV is a new phenomenon in Indian agriculture; once the technology is fully implemented in all the agriculture states, it would reflect the actual picture of societal, economic and environmental acceptability and adaptability.

The governance of civilian UAV in India can be said to be effective only when it maintains the culture-specific values of the society where it is deployed. Apart from it, for better governance of civilian UAV in Indian agriculture, 
accountability and responsibility of the actors engaged in the deployment of the technology is an utmost important task. Thus, taking and ensuring the care of values, upholding the culture-specific values (social, economic and environmental) can enable civilian UAVs as a responsible innovation in Indian crop insurance applications.

Acknowledgements The authors would like to acknowledge the anonymous reviewers who gave their constructive comments on the paper. The comments from the reviewers helped in the finalisation of the article.

\section{Compliance with ethical standards}

Conflict of interest On behalf of all authors, the corresponding author states that there is no conflict of interest.

\section{References}

1. Thompson PB (2007) Agricultural sustainability: what it is and what it is not. Int J Agric Sustain 5(1):5-16

2. Nelson CJ (2007) Sustainability of agriculture: issues, observations and outlook. J Crop Improv 19(1-2):1-24

3. Hellström T (2003) Systemic innovation and risk: technology assessment and the challenge of responsible innovation. Technol Soc 25(3):369-384

4. Barbier M, Elzen B (2012) System innovations, knowledge regimes, and design practices towards transitions for sustainable agriculture. INRA, Paris

5. Elzen B, Geels FW, Green K (eds) (2004) System innovation and the transition to sustainability: theory, evidence and policy. Edward Elgar, Northhampton

6. North DC (1991) Institutions. J Econ Perspect 5(1):97-112

7. National Research Council (2019) Toward sustainable agricultural systems in the 21st century [internet]. The National Academies Press, Washington; 2010 [cited 2019 Jan 30]. https://www. nap.edu/catalog/12832/toward-sustainable-agricultural-syste ms-in-the-21st-century

8. Davis CG, Langham MR (1995) Agricultural industrialization and sustainable development: a global perspective. J Agric Appl Econ 27(01):21-34

9. Chamuah A, Singh R (2020) Responsibility and accountability in the governance of civilian UAV for crop insurance applications in India. In: Avtar R, Watanabe T (eds) Unmanned aerial vehicle: applications in agriculture and environment [Internet]. Springer, Cham, pp 189-199. https://doi.org/10.1007/978-3-030-27157 $-2 \_14$

10. Mobegi VO, Kaburi SN, Kombo A, Achuti DM, Matoke DA, Ombasa BB et al (2012) Influence of new technology on financial performance; a case of small scale tea industry in Kebirigo, Kenya. Glob Adv Res J Econ Account Financ (GARJEAF) 1(6):19

11. Rotolo D, Hicks D, Martin BR (2015) What is an emerging technology? Res Policy 44(10):1827-1843

12. Von Schomberg $R$ (2013) A vision of responsible research and innovation. In: Owen R, Bessant J, Heintz M (eds) Responsible innovation: managing the responsible emergence of science and innovation in society, vol 1. Wiley, pp 51-74

13. Stilgoe J, Owen R, Macnaghten P (2013) Developing a framework for responsible innovation. Res Policy 42(9):1568-1580

14. Setiawan AD, Singh $R$ (2015) Responsible innovation in practice: the adoption of solar PV in telecom towers in Indonesia.
In: Koops B-J, Oosterlaken I, Romijn H, Swierstra T, van den Hoven J (eds) Responsible innovation 2 [Internet]. Springer, Cham [cited 2018 Oct 22], pp 225-243. http://link.springer. com/10.1007/978-3-319-17308-5_12

15. van den Hoven J (2013) Value sensitive design and responsible innovation. In: Responsible innovation [Internet]. Wiley, [cited 2018 Nov 17]. pp 75-83. https://onlinelibrary.wiley.com/doi/ abs/10.1002/9781118551424.ch4

16. Burget M, Bardone E, Pedaste M (2017) Definitions and conceptual dimensions of responsible research and innovation: a literature review. Sci Eng Ethics 23(1):1-19

17. Zahinos A (2015) Responsible innovation at the firm-level tracing in car industry [Internet]. Ph.D. thesis. Universitat Politecnica De Catalunya, Barcelona [cited 2019 Jun 5]. https ://upcommons.upc.edu/bitstream/handle/2117/96212/TAZR1 de1.pdf?isAllowed $=y$ \&sequence $=1$

18. Lundvall B (2007) National innovation systems-analytical concept and development tool. Ind Innov 14(1):95-119

19. Freeman C (1995) The 'national system of innovation' in historical perspective. Camb J Econ 19(1):5-24

20. Malerba F (2002) Sectoral systems of innovation and production. Res Policy. 31:247-264

21. Malerba F, Mani S (2009) Sectoral systems of innovation and production in developing countries: actors, structure and evolution. Edward Elgar Publishing, Cheltenham

22. Carlsson B, Stankiewicz R (1991) On the nature, function and composition of technological systems. J Evol Econ. 1(2):93-118

23. Markard J, Truffer B (2008) Technological innovation systems and the multi-level perspective: towards an integrated framework. Res Policy 4(37):596-615

24. Bergek A, Jacobsson S, Carlsson B, Lindmark S, Rickne A (2008) Analyzing the functional dynamics of technological innovation systems: a scheme of analysis. Res Policy 37(3):407-429

25. Singh R, Kroesen $\mathrm{O}$ (2012) Understanding responsible innovation from de-veloping countries perspectives. Netherland Organization for Scientific Research \& TU Centre for Ethics and Technology, The Hague

26. Zahinos A, Singh R, González-Benítez M (2013) Moving toward responsible innovation approach in the automotive industry: the SEAT case, $\mathrm{p} 9$

27. Owen R, Bessant JR, Heintz M (eds) (2013) Responsible innovation: managing the responsible emergence of science and innovation in society. Wiley, Chichester

28. Axelsson R, Angelstam P, Degerman E, Teitelbaum S, Andersson K, Elbakidze M et al (2013) Social and cultural sustainability: criteria, indicators, verifier variables for measurement and maps for visualization to support planning. AMBIO 42(2):215-228

29. Gonzalez J, New W (2015) perspectives on technology, values, and ethics: theoretical and practical. Springer, Berlin

30. Hoven VD, Vermaas J, Poel IV (2015) Handbook of ethics, values, and technological design: sources, theory, values and application domains. In: van den Hoven J. Springer [Internet] [cited 2018 Dec 5]. https://www.springer.com/in/book/9789400769 694

31. Schutt RK (2011) Investigating the social world: the process and practice of research. Pine Forge Press, Newbury Park

32. Dudovskiy J (2018) Snowball sampling [Internet]. ResearchMethodology [cited 2018 Oct 22]. https://research-methodolog y.net/sampling-in-primary-data-collection/snowball-sampling/

33. Pigford A-AE, Hickey GM, Klerkx L (2018) Beyond agricultural innovation systems? Exploring an agricultural innovation ecosystems approach for niche design and development in sustainability transitions. Agric Syst 164:116-121 
34. El Bilali H, Allahyari MS (2018) Transition towards sustainability in agriculture and food systems: role of information and communication technologies. Inf Process Agric 5(4):456-464

35. ICAO (2005) Global air traffic management operational concept [Internet]. International Civil Aviation Organization. https:// www.icao.int/Meetings/anconf12/Document\%20Archive/9854_ cons_en[1].pdf

36. Xiang $H$, Tian L (2011) Development of a low-cost agricultural remote sensing system based on an autonomous unmanned aerial vehicle (UAV). Biosyst Eng 108(2):174-190

37. Siebert S, Teizer J (2013) Mobile 3D mapping for surveying earthwork using an unmanned aerial vehicle (UAV). Montreal, Canada [cited 2019 Jan 25]. http://www.iaarc.org/publications/proce edings_of_the_30th_isarc/mobile_3d_mapping_for_surve ying_earthwork_using_an_unmanned_aerial_vehicle_uav.html

38. Luo C, Wang Y, Hong Y, Chen W, Ding X, Zhu Y et al (2019) Minimizing data collection latency with unmanned aerial vehicle in wireless sensor networks. J Comb Optim [Internet] [cited 2019 Sep 2]. http://link.springer.com/10.1007/s10878-019-00434-w

39. Faraz A (2016) Data on wings: a close look at drones in India [Internet]. PwC [cited 2018 Oct 31]. https://www.pwc.in/consu Iting/financial-services/fintech/fintech-insights/data-on-wings -a-close-look-at-drones-in-india.html

40. Dubey S (2018) Interview schedule: UAV technology and crop insurance

41. Lohia S (2019) Drone regulations 1.0 can fetch India major slice of $\$ 100$ billion industry [Internet]. Moneycontrol [cited 2019 Jan 21]. https://www.moneycontrol.com/news/india/drone-regul ations-1-0-can-fetch-india-major-slice-of-100-billion-industry3358411.html

42. GoldmanSachs (2019) Drones: reporting for work [Internet]. Goldman Sachs [cited 2019 Jan 21]. http://www.goldmansac hs.com/insights/technology-driving-innovation/drones/

43. Lalan V (2019) Interview schedule: civilian UAV technology and crop insurance

44. Nickel PJ (2015) Design for the value of trust. In: Handbook of ethics, values, and technological design: sources, theory, values and application domains [Internet]. Springer, New York [cited 2019 Aug 24], pp 551-568. https://link.springer.com/referencew orkentry/10.1007\%2F978-94-007-6970-0_21

45. Ray S (2017) Interview schedule: UAV technology and crop insurance

46. van de Poel I, Sand M (2018) Varieties of responsibility: two problems of responsible innovation. Synthese [Internet] [cited 2019 Feb 7]. http://link.springer.com/10.1007/s11229-018-01951-7

47. Manda S (2017) Interview schedule: UAV technology and responsible innovation

48. Honkavaara E, Saari H, Kaivosoja J, Pölönen I, Hakala T, Litkey P et al (2013) Processing and assessment of spectrometric, stereoscopic imagery collected using a lightweight UAV spectral camera for precision agriculture. Remote Sens 5(10):5006-5039

49. Stoker G (1998) Governance as theory: five propositions. Int Soc Sci J 50(155):17-28

50. Devaney L (2016) Good governance? Perceptions of accountability, transparency and effectiveness in Irish food risk governance. Food Policy 62:1-10

51. Lee RG, Petts J (2013) Adaptive governance for responsible innovation. In: Responsible innovation [Internet]. Wiley-Blackwell [cited 2018 Oct 13]. pp 143-164. https://onlinelibrary.wiley.com/ doi/abs/10.1002/9781118551424.ch8

52. Mohamed N, Al-Jaroodi J, Jawhar I, Idries A, Mohammed F (2018) Unmanned aerial vehicles applications in future smart cities. Technol Forecast Soc Change [Internet] [cited 2018 Nov 10]. https://linkinghub.elsevier.com/retrieve/pii/S00401625173149 68

SN Applied Sciences

APRINGER NATURE journa
53. Nakamura H, Kajikawa Y (2018) Regulation and innovation: how should small unmanned aerial vehicles be regulated? Technol Forecast Soc Change 128:262-274

54. Mishra S, Singh R (2018) Responsible innovation: a new approach to address the theoretical gaps for innovating in emerging e-mobility sector. In: Ferri F, Dwyer N, Raicevich S, Grifoni P, Altiok H, Andersen HT, et al. (eds) Governance and sustainability of responsible research and innovation processes: cases and experiences [Internet]. Springer, Cham [cited 2018 Oct 31]. pp 93-99. (Springer Briefs in Research and Innovation Governance). https://doi.org/10.1007/978-3-319-73105-6_12

55. van de Poel I, Robaey Z (2017) Safe-by-design: from safety to responsibility. NanoEthics. 11(3):297-306

56. NECTAR (2017) Interview schedule: UAV technology and crop insurance

57. DGCA (2018) Interview schedule: regulations of UAV technology

58. Acevedo-Whitehouse K, Duffus ALJ (2009) Effects of environmental change on wildlife health. Philos Trans R Soc B Biol Sci 364(1534):3429-3438

59. Agripb (2016) Agriculture Punjab, India [Internet] [cited 2019 Aug 12]. http://agripb.gov.in/home.php?page $=$ cropc

60. Greenwood F (2016) Drones on the horizon: new frontier in agricultural innovation: ICT update [Internet]. ICT update [cited 2019 Apr 4]. http://ictupdate.cta.int/2016/04/21/drones-on-thehorizon-new-frontier-in-agricultural-innovation/

61. Siddiqui S (2016) Sri Lanka's drone pioneers [cited 2019 Apr 4]. https://cgspace.cgiar.org/handle/10568/76397

62. Le Q (2016) A bird's eye view on Africa's rice irrigation systems: ICT update [Internet]. ICT update [cited 2019 Apr 4]. http://ictup date.cta.int/2016/04/21/a-birds-eye-view-on-africas-rice-irrig ation-systems/

63. Cressman K (2016) Preventing the spread of desert locust swarms: ICT update [Internet]. ICT update [cited 2019 Apr 4]. http://ictupdate.cta.int/2016/04/21/preventing-the-spread-ofdesert-locust-swarms/

64. Tushev K, BewickT, Ellis (2016) PPgis.net Blog: documenting illegal land occupancy using drones [Internet]. PPgis.net Blog [cited 2019 Apr 4]. http://participatorygis.blogspot.com/2016/05/ documenting-illegal-land-occupancy.html

65. Bukchin S, Kerret D (2018) Food for hope: the role of personal resources in farmers' adoption of green technology. Sustainability $10(5): 1615$

66. OECD (2001) Adoption of Technologies for sustainable farming systems Wageningen workshop proceedings [Internet]. Wageningen University, France [cited 2019 Nov 25], pp 1-149. https ://www.oecd.org/greengrowth/sustainable-agriculture/27397 71.pdf

67. Bongiovanni R, Lowenberg-Deboer J (2004) Precision agriculture and sustainability. Precis Agric 5(4):359-387

68. Zilberman D, Khanna M, Lipper L (1997) Economics of new technologies for sustainable agriculture. Aust J Agric Resour Econ 41(1):63-80

69. Chamuah A (2015) Decelerating tea productivity in Assam: innovation systems perspectives. M.Phil. dissertation. Jawaharlal Nehru University, New Delhi

70. Yang F, Wang K, Han Y, Qiao Z (2018) A cloud-based digital farm management system for vegetable production process management and quality traceability. Sustainability 10(11):4007

Publisher's Note Springer Nature remains neutral with regard to jurisdictional claims in published maps and institutional affiliations. 